\title{
Desplazamiento forzado interno, seguridad pública y gobernanza en México
}

\author{
Ignacio César Cruz Islas \\ El Colegio del Estado de Hidalgo
}

\begin{abstract}
Resumen
El desplazamiento forzado interno surgió como uno de los motivos para que la población en México cambie su lugar de residencia. Obedece a diferentes fenómenos de carácter social o de origen natural, sin embargo, la grave crisis de seguridad pública y violencia generalizada que se vive en el país se ha sumado a sus causas. Existen distintos actores involucrados en el desplazamiento forzado interno motivado por condiciones de inseguridad pública, presentándose violación grave a los derechos humanos que ha sido poco reconocida por la autoridad y permanece sin cuantificarse adecuadamente. Por ese motivo en este trabajo se explora el vínculo del desplazamiento forzado interno con la incidencia delictiva usando datos de la Encuesta Nacional de Victimización y Percepción sobre Seguridad Pública (ENVIPE). Se pretende aportar elementos de discusión para la atención de dicho fenómeno social en el marco de la gobernanza.
\end{abstract}

Palabras clave: Desplazamiento forzado interno, seguridad pública, gobernanza, México.

\section{Internal forced displacement, public security and governance in Mexico}

\begin{abstract}
In the case of Mexico internal forced displacement has emerged as one of the reasons for migration. It obeys to different phenomena of social character or natural origin. Nevertheless, the serious crisis of public security and generalized violence that has been lived in the country has been added to its causes. There are different actors involved and constitutes a serious violation to human rights. It has been little recognized by the authority and remains insuficiently quantified. For that reason, the link between internal forced displacement and criminal incidence is explored. Data from National Survey of Victimization and Perception of Public Safety (ENVIPE) are used. The focus is to provide elements of discussion to address this social phenomenon in the framework of governance.
\end{abstract}

Keywords: Internal forced displacement, public security, governance, Mexico.

Artículo recibido el 04 de mayo de 2019 y aprobado el 09 de enero de 2020. 


\section{INTRODUCCIÓN}

$\mathrm{E}$

1 fenómeno migratorio asociado con la búsqueda de mejores condiciones de vida ha crecido en volumen e intensidad en las décadas más recientes, a la vez que resulta más complejo y diverso. La globalización, en sus diversas expresiones, ha jugado un rol fundamental para ello, sólo comprensible si consideramos que a la par de los beneficios del crecimiento económico, también han aumentado las brechas de desigualdad en el desarrollo entre países y regiones. Se trata, sin embargo, de un acto voluntario producto de una decisión individual o familiar, que se encuentra determinado por dicha aspiración para aumentar el nivel de vida, así como el bienestar individual o de la familia. El desplazamiento forzado, en cambio, está determinado por factores ajenos al control de los individuos y las personas que les rodean en el seno del hogar.

En el caso de México, el desplazamiento forzado es un fenómeno que fundamentalmente había sido producto de conflictos sociales, entre los que destacan la intolerancia religiosa, las disputas entre comunidades, así como las controversias por la propiedad de la tierra y sus recursos. También ha obedecido a fenómenos de origen natural que llevan a la población a abandonar en forma masiva comunidades enteras, tales es el caso de inundaciones, terremotos o erupciones volcánicas, por mencionar a los más comunes.

Sin embargo, en los últimos años se suma la influencia de la inseguridad pública creciente, que determina la intervención de Fuerzas Armadas, policías de distintos órdenes, y el surgimiento de grupos de autodefensa; generando en los hechos zonas de exclusión (CMDPDH, 2014). Lo cual se constituye en una violación grave a los derechos humanos que ha sido poco reconocida por la autoridad y permanece sin cuantificarse adecuadamente. Constituyéndose en un problema para la gobernabilidad democrática o gobernanza.

Este concepto resulta descriptivo más que teórico y hace referencia a formas de gobernar distintas de la gubernamental burocrática, pues incorpora mecanismos de mercado y sociedad, y pretendidas nuevas formas de relacionarse entre gobierno y sociedad civil, organizada o no. De modo tal que las relaciones entre la instancia de gobierno 
y la sociedad cambian según las condiciones y definen el patrón de gobierno. Supone una sociedad fuerte, independiente y autónoma, así como la coordinación, interdependencia y formación de redes (Serna, 2010).

Una sociedad fuerte, sin embargo, reconoce y es capaz de ejercer plenamente sus derechos. Eso no ocurre con la población desplazada por la inseguridad pública, pues no existen condiciones que permitan garantizar mínimamente algunos derechos fundamentales como el derecho a la vida, derecho a la integridad y la seguridad personal, derecho a la libertad de tránsito y residencia, así como a la salvaguarda de sus bienes. El gobierno, por su parte, ha sido incapaz de proveer esas condiciones mínimas.

El de los derechos fundamentales es un debate profuso en la actualidad. Particularmente, tras la modificación constitucional que impulsa el principio pro persona en la interpretación jurídica:

Las normas relativas a los Derechos Humanos se interpretarán de conformidad con esta Constitución y con los tratados internacionales de la materia favoreciendo en todo tiempo a las personas la protección más amplia (Constitución Política de los Estados Unidos Mexicanos).

Dicha protección más amplia lleva a considerar que las razones fundamentales por las que surge el estado nación son la necesidad de protección, estabilidad y normatividad común. Es decir, la función de seguridad que brinda el estado es uno de sus fundamentos básicos, pues implica la preservación de un orden estable para una convivencia armónica en la que se regulan las relaciones y conductas de las personas. De acuerdo con Max Weber, el Estado es una estructura de dominación que "ejerce con éxito el monopolio de la coerción física legítima dentro de un territorio determinado" (García, 2002). Dicha coerción física legítima es el rol central de la seguridad pública.

El desplazamiento interno forzado por inseguridad pública, entonces, pone en entredicho el rol central del estado como garante y protector de los derechos fundamentales. Por ese motivo en este trabajo se estima la incidencia de dicho fenómeno social con datos de la Encuesta Nacional de Victimización y Percepción sobre Seguridad Pública (ENVIPE), de los años 2011 y 2016, buscando mediante un análisis estadístico exploratorio aportar elementos de discusión para la atención de dicho fenómeno social en el marco de la gobernanza. 
Al efecto se parte de una discusión en torno al vínculo entre desplazamiento forzado interno y derechos humanos, para pasar después a explorar su correlación con la incidencia delictiva. En este caso, además de la tasa de incidencia de delitos en general, se pondera la incidencia de delitos considerados de alto impacto; concretamente, amenazas, extorsión, homicidio y secuestro. Otro aspecto que se contempla por su relación con el rol del estado es el gasto en seguridad pública.

\section{Desplazamiento forzado interno y derechos humanos}

La discusión en torno a los factores constitutivos de desplazamiento forzado en América Latina toma fuerza debido al caso de Colombia, país donde el fenómeno comenzó a considerarse como una problemática de interés para distintos ámbitos de protección de los derechos humanos desde la década de 1980.

Abordada como tal por el Estado colombiano hasta 1995, se visibiliza como un problema social a considerar por las políticas públicas (Aponte, 2011). Es pertinente por ello mencionar las similitudes, toda proporción guardada, entre la violencia presente en Colombia en aquella época, en buena medida causa del desplazamiento forzado de indígenas y campesinos, y la que se observa en México actualmente. Llevándonos, por lógica, a plantear como cuestión esencial que el desplazamiento forzado interno sea visibilizado por el Estado mexicano.

Es de dominio público que México transita por una grave crisis se seguridad pública y violencia generalizada, particularmente desde el inicio de la "guerra contra el narcotráfico" en 2006. De acuerdo con la Comisión Interamericana de los Derechos Humanos (CIDH), la violencia y su impacto social es elevado y no se observan cambios sustanciales en la política de seguridad del gobierno mexicano. Caracterizándose la situación actual de inseguridad pública por violencia extrema; altos niveles de impunidad y una deficiente atención a víctimas y sus familias. Afectando en mayor medida a personas en pobreza, migrantes o desplazados, entre otros (CIDH, 2015).

Una manera de ilustrar la tendencia en los niveles de violencia es la incidencia de homicidios dolosos reportados en averiguaciones previas o carpetas de investigación. De acuerdo con la información oficial disponible, tras disminuir de 17.8 homicidios por cien mil habitantes en 1997 a 9.4 en 2007, la tasa de homicidios dolosos alcanzó 19.8 en 2011 y 24.3 en 2018 (Figura 1). 
Figura 1. Tasa de homicidios dolosos en México 1997-2018

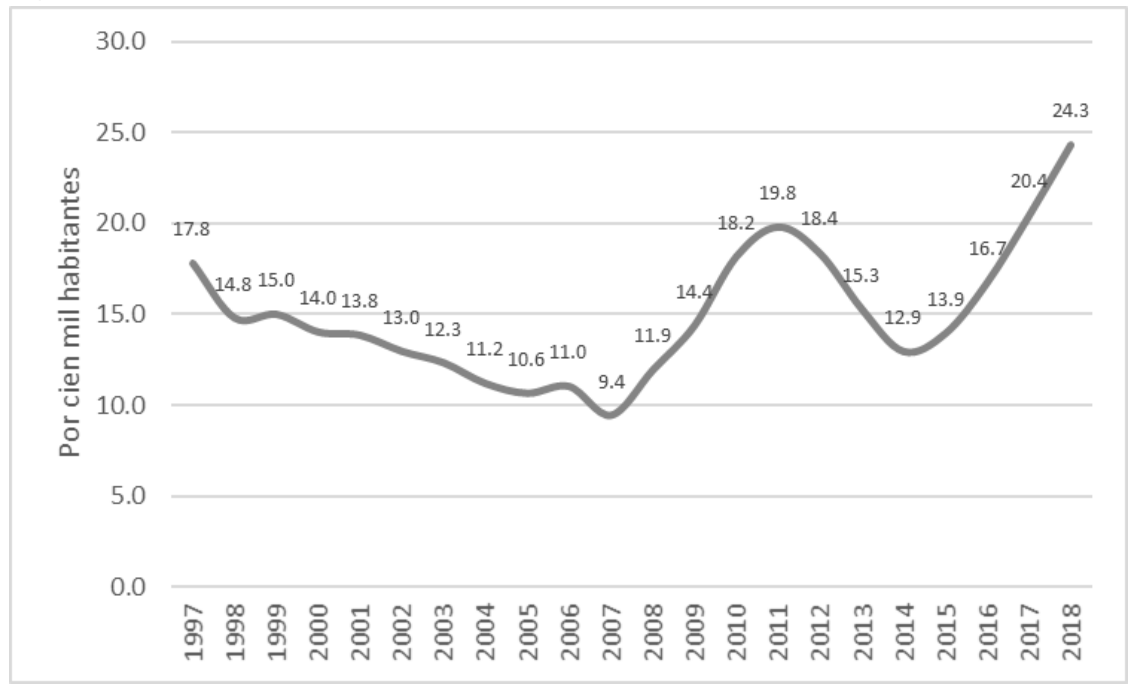

Fuente: Elaboración propia con base en datos el Secretariado Ejecutivo del Sistema Nacional de Seguridad Pública y consejo Nacional de Población.

Se trata, como puede verse, de una situación grave que refleja la incidencia de violencia en diversas formas. Violencia que, según la CIDH, proviene de diversos agentes estatales - tales como cuerpos policíacos e integrantes de las Fuerzas Armadas-, el crimen organizado, en ciertos casos a las policías "comunitarias" o "autodefensas", y algunas fuerzas privadas de seguridad; que se asocia con la desigualdad social y económica; la existencia de rutas migratorias, de tráfico de armas y drogas; así como fallas estructurales en el andamiaje del sistema de impartición de justicia (CIDH, 2015).

La ratificación de distintos tratados internacionales en materia de derechos humanos, y su elevación a normas con jerarquía constitucional incluso, no han tenido el resultado deseado. Tal es el caso de la garantía y protección a los derechos humanos:

En los Estados Unidos Mexicanos todas las personas gozarán de los derechos humanos reconocidos en esta Constitución y en los tratados internacionales de los que el Estado Mexicano sea parte, así como de las garantías para su protección, cuyo ejercicio no podrá restringirse ni suspenderse, salvo en los casos y bajo las condiciones que esta Constitución establece... (DOF, 2011). 
En este marco, el desplazamiento forzado interno es una violación grave a los derechos humanos, como mencionamos, poco reconocida por la autoridad, que permanece sin cuantificarse en toda su magnitud. Se presume que afecta particularmente a adultos mayores, mujeres, niños e indígenas, particularmente en condiciones rezago social, lo que sugiere que se trata de personas y familias en condiciones de muy alta vulnerabilidad en materia de vivienda, educación, salud o empleo (CIDH, 2015).

En materia legislativa, sin un marco de carácter general, sólo en dos entidades del país (Chiapas y Guerrero) existe una ley específica en materia de desplazamiento forzado interno. Se reconocen como causas intolerancia religiosa, problemas intracomunitarios, disputas agrarias, conflictos armados e inseguridad creciente; y que no existen cifras oficiales concretas sobre las personas desplazadas, por lo que el estudio del fenómeno se torna complejo (POGEG, 2014).

La Comisión de Derechos Humanos de la Organización de las Naciones Unidas define como desplazadas internas a "las personas o grupos de personas que se han visto forzadas u obligadas a escapar o huir de su hogar o de su lugar de residencia habitual, en particular como resultado o para evitar los efectos de un conflicto armado, de situaciones de violencia generalizada, de violaciones de los derechos humanos o de catástrofes naturales o provocadas por el ser humano, $\mathrm{y}$ que no han cruzado una frontera estatal internacionalmente reconocida" (CRI, 1998).

Las personas en esta situación "disfrutarán en condiciones de igualdad de los mismos derechos y libertades que (se les) reconocen a los demás habitantes del país", y que "no serán objeto de discriminación alguna". Asimismo, "tienen derecho a solicitar y recibir protección y asistencia humanitaria" por parte de las autoridades nacionales. Éstas, a su vez, "tienen la obligación y la responsabilidad de proporcionar protección y asistencia humanitaria a los desplazados internos que se encuentren en el ámbito de su jurisdicción" (CRI, 1998).

\section{Desplazamiento forzado interno e incidencia de delitos}

Las estimaciones sobre la cantidad de personas desplazadas en México son tan diversas como las fuentes mismas. El Informe Global de Desplazamiento Forzado 2014, señala que alrededor de $160 \mathrm{mil}$ personas han sido obligadas a dejar su residencia habitual en el país, debido principalmente a situaciones de violencia generalizada. El 
fenómeno comenzó a ser estudiado en la década de 1990 y se estima que 20 mil personas fueron desplazadas en 2013. En ese año las entidades más afectadas fueron Chihuahua, Tamaulipas, Durango, Michoacán, Nuevo León, Sinaloa, Sonora y Guerrero (The Global Overview, 2014).

La Comisión Nacional de Derechos Humanos (CNDH), entidad creada en 1990, señala que entre las principales causas de desplazamiento forzado interno en el país se encuentra el levantamiento del Ejército Zapatista de Liberación Nacional; la violencia generada por intolerancia religiosa y las violaciones graves a los derechos humanos en diversos puntos del territorio nacional; desastres naturales ligados al cambio climático; violencia por enfrentamientos entre grupos delincuenciales; el surgimiento de autodefensas; el ejercicio de la actividad periodística; y, la ejecución de algunos proyectos de infraestructura (CNDH, 2016).

En la actualidad, el desplazamiento forzado interno se vincula estrechamente con la inseguridad pública y la estrategia de combate a la delincuencia organizada. La CNDH establece que las formas de violencia incluyen extorsión, amenazas, destrucción de casa habitación, homicidio, secuestro y reclutamiento forzado (CNDH, 2016). Es probable, por tanto, que exista correlación entre la incidencia de delitos y el desplazamiento forzado interno.

Datos de la Encuesta Nacional de Victimización y Percepción sobre Seguridad Pública - ENVIPE- (INEGI, 2016), muestran que la tasa de incidencia delictiva pasó de 30 mil 535 a 35 mil 497 delitos por cien mil habitantes entre 2010 y 2015 . Además, la proporción de población de 18 años o más que fue víctima de algún delito creció de 24.0 a 28.2 por ciento. Los delitos más comunes en 2015 fueron robo o asalto en calle o transporte público (28.2 por ciento del total de delitos) y extorsión (24.2 por ciento).

En lo que toca a las entidades del país, durante 2010 la tasa de incidencia de delitos fue "muy alta" en Aguascalientes, Ciudad de México, Chihuahua, Sonora, Quintana Roo y Yucatán, y "alta” en Baja California, Estado de México, Guerrero, Jalisco, Nayarit, Nuevo León, San Luis Potosí, Sinaloa y Tabasco (Figura 2). ${ }^{1}$ Patrón que se modifica en cierto grado para 2015, año en que dicha tasa de incidencia fue "muy alta" en Ciudad de México, Estado de México, Morelos, Guerrero

1 Para clasificar la información se utilizó el Método de Optimización de Jenks, que identifica los puntos de ruptura relativos a los datos (natural breaks) en una distribución. A través de un proceso iterativo basado en pruebas de bondad del ajuste permite obtener los grupos de mayor homogeneidad interna. 
y Jalisco, mientras que fue "alta" para Aguascalientes, Baja California, Chihuahua, Guanajuato, Querétaro, Quintana Roo, Sonora, Tabasco y Tlaxcala (Figura 3).

Figura 2. Tasa de incidencia de delitos por entidad federativa 2010

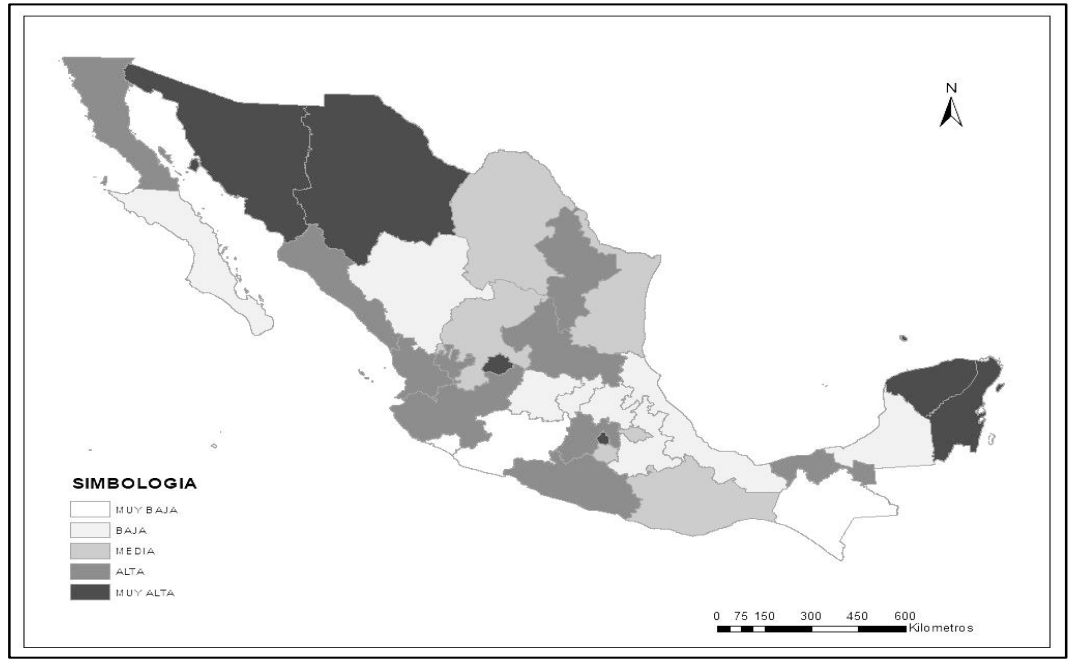

Fuente: Elaboración propia con datos del Secretariado Ejecutivo del Sistema Nacional de Seguridad Pública.

Figura 3. Tasa de incidencia de delitos por entidad federativa 2015



Fuente: Elaboración propia con datos del Secretariado Ejecutivo del Sistema Nacional de Seguridad Pública 
En lo que toca al desplazamiento forzado interno asociado con la incidencia delictiva, la información correspondiente a 2010 indica que en 1.3 por ciento de las viviendas de la muestra de la ENVIPE decidieron cambiarse de vivienda o lugar de residencia para protegerse de la delincuencia. Sin embargo, la cifra aumentó considerablemente hacia 2015 en 20.2 por ciento de las viviendas declararon en el mismo sentido. Incremento que sugiere la naturaleza e impacto de dicho problema social.

En cuanto a las entidades federativas, durante 2010 hubo mayor incidencia de desplazamiento forzado interno por dicho motivo en Aguascalientes (3.6 por ciento) con muy alta proporción de viviendas; así como en Sinaloa (2.8 por ciento), Zacatecas (2.5 por ciento), Chihuahua (2.2 por ciento), Nayarit (2.2 por ciento), Quintana Roo (2.1 por ciento) y Baja California (1.9 por ciento), con alta proporción (Figura 4).

Figura 4. Proporción de viviendas con desplazamiento forzado 2010



Fuente: Elaboración propia con datos de ENVIPE 2011

En 2015, además del incremento señalado arriba, cambia su distribución geográfica, sugiriendo una aguda diversificación espacial del fenómeno asociado con la incidencia delictiva (Figura 5). La proporción de viviendas donde declararon haber cambiado de vivienda o lugar de residencia motivados por la delincuencia fue muy alta, en el Estado de México (31.7 por ciento), Tamaulipas (29.4 por 
ciento), Guerrero (27.0 por ciento), Tlaxcala (26.4 por ciento), Tabasco (25.3 por ciento) y Morelos (24.8 por ciento). Así mismo, fue alta en Coahuila (24.0 por ciento), Durango (23.3 por ciento), Veracruz (21.9 por ciento), Chihuahua (21.3 por ciento), Nayarit (20.6 por ciento), Nuevo León (20.4 por ciento), Ciudad de México (19.9 por ciento), Oaxaca (19.5 por ciento) y Colima (19.5 por ciento).

Figura 5. Proporción de viviendas con desplazamiento forzado 2015

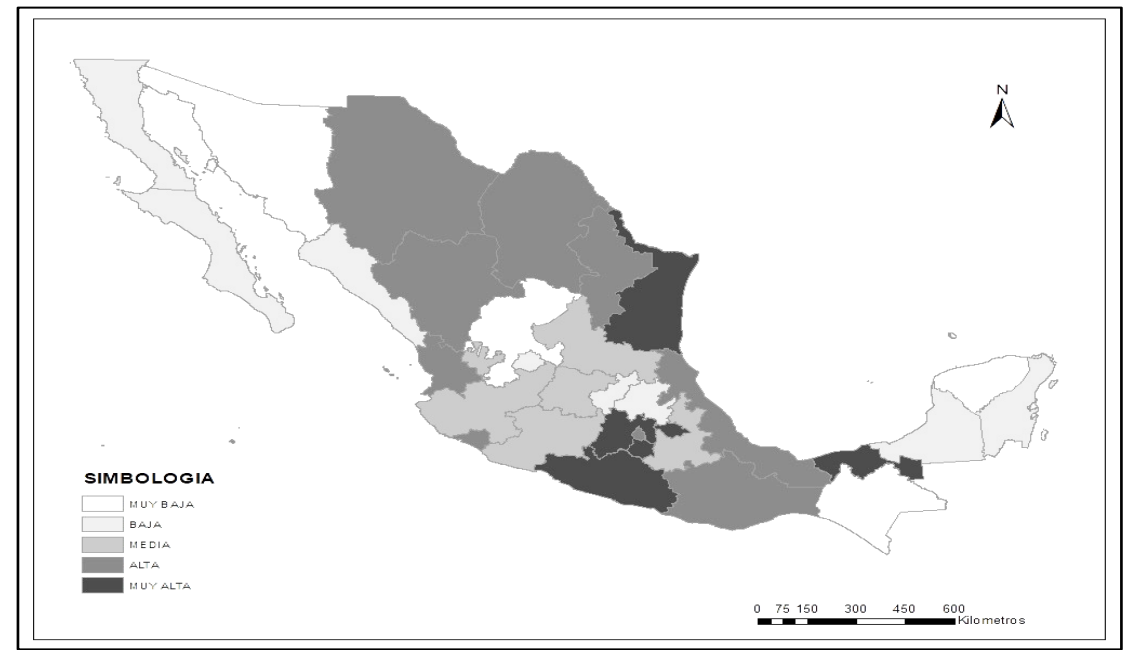

Fuente: Eelaboración propia con datos de ENVIPE 2016

Al vincular los datos sobre la proporción de viviendas donde declaran haber cambiado de residencia por cuestiones de seguridad, con la incidencia de cierto tipo de delitos, en la Tabla 1 encontramos que la correlación de Pearson es positiva y significativa, aunque moderada, en el caso del delito de secuestro (0.520).

En cambio, cuando se trata de la percepción de inseguridad respecto a distintos núcleos geográficos donde se asienta la vivienda, en todos los casos la correlación es positiva y estadísticamente significativa. Moderada en el caso de la percepción de inseguridad en la colonia o localidad (0.497); y alta en lo que toca al municipio o delegación (0.670) y la entidad federativa (0.731), como se aprecia en la Tabla 2.

Dos aspectos importantes en este caso son, por un lado, la cifra de delitos no denunciados o que no derivaron en averiguación previa. Dicha "cifra negra" fue de 93.7 por ciento en el país durante 2015 (INEGI, 2016a). Por otro, el nivel de confianza en las autoridades de la entidad y el municipio. 
Tabla 1. Correlación de Pearson entre variables de interés por entidad federativa 2015

$(\mathrm{N}=32) \quad$ Tasa de incidencia delictiva (por 100,000 habitantes)

Amenazas Extorsión Homicidio Secuestro

Porcentaje de viviendas

con desplazamiento

forzado por motivos de

$-0.090$

0.122

0.086

$0.520^{* *}$

seguridad

Fuente: Elaboración propia con base en datos de ENVIPE 2016.

${ }^{* *}$ ) Significativa al nivel 0.01 (bilateral)

Tabla 2. Correlación de Pearson entre variables de interés por entidad federativa 2015

$(\mathrm{N}=32)$

Percepción de inseguridad

\begin{tabular}{ccc}
$\begin{array}{c}\text { En la colonia o } \\
\text { localidad }\end{array}$ & $\begin{array}{c}\text { En el municipio } \\
\text { o delegación }\end{array}$ & $\begin{array}{c}\text { En la entidad } \\
\text { federativa }\end{array}$ \\
\hline
\end{tabular}

Porcentaje de

viviendas con

desplazamiento forzado por

$0.497^{* *} \quad 0.670^{* *}$

$0.731^{* *}$

motivos de seguridad

Fuente: Elaboración propia con base en datos de ENVIPE 2016.

(**) Significativa al nivel 0.01 (bilateral)

De acuerdo con INEGI (2016a), entre las razones para no denunciar delitos ante la autoridad competente por parte de las víctimas, 63 por ciento se atribuyen a la propia autoridad: temor a una extorsión, pérdida de tiempo, trámites largos y tediosos, desconfianza, o actitud hostil. Igualmente existe un elevado nivel de percepción sobre la corrupción de diversas autoridades: Policía de Tránsito (76.1 por ciento), Policía Preventiva Municipal (66.7 por ciento), Ministerio Público y procuradurías estatales (65.8 por ciento), jueces (65.1 por ciento), Policía Ministerial o Judicial (63.3 por ciento), Policía Estatal (62.9 por ciento), Procuraduría General de la República (59.6 por ciento) y Policía Federal (55.3 por ciento).

\section{Seguridad pública y gasto}

El tema de la inseguridad pública, origen de la forma de desplazamiento interno forzado expuesta en los apartados previos, ocupa por diversos motivos un lugar preponderante en la agenda gubernamental, así 
como el interés de diversos grupos y sectores de la sociedad. Entre los aspectos a debate se encuentra el rol del estado en el escenario actual.

Esto entendiendo al estado desde la definición clásica de Max Weber (citado por Jiménez y Ramírez, 2008: 16), "como una estructura de dominación que ejerce con éxito el monopolio de la coerción física legítima dentro de un territorio determinado". Al que se le opone la coerción física "no legítima", es decir, la que ejercen grupos e individuos que actúan al margen de la Ley. Aspecto que, para ciertos sectores de opinión y análisis, sugiere la existencia de un estado fallido en nuestro país. En tanto que para otros supone la necesidad de reformar el constructo actual del estado mexicano o al menos de su sistema de justicia penal.

Para el caso que nos ocupa, la noción de estado fallido apunta a la propuesta de Noam Chomsky (citado por Zapata, 2014: 91), quien establece que una de las características particulares de los estados fallidos es que son incapaces de proteger de la violencia a la población. Otra característica se asocia con las prioridades de tomadores de decisiones, más enfocadas a su juicio a privilegiar a ciertos sectores o grupos de población en detrimento de otros.

Siguiendo las ideas de Luis Enrique Chase (2002), cabe anotar que toda reforma del estado o al sistema de justicia penal resulta de un proceso histórico de carácter contingente. Proceso, que dependerá de las doctrinas jurídicas y administrativas existentes, así como de los movimientos políticos presentes o emergentes. Estará influenciada además por la ideología y paradigmas dominantes en un momento dado del tiempo. Lo que en la lógica reciente nos remite a la transición del estado del bienestar al estado neoliberal, justificado en términos fiscales, administrativos y políticos en el marco de la globalización económica.

Recordemos, como nos dice Jaime Cárdenas (2017), que el Estado del bienestar se vincula con el reconocimiento constitucional y legal de derechos económicos, sociales y culturales, así como ambientales; generando un nuevo orden social que se consolida entre la Segunda Guerra Mundial y la década de 1970, llevando a la construcción de sociedades más equitativas y armónicas. Para luego comenzar a ser desmantelado tras la recuperación de los principios de liberalismo económico y las acciones gubernamentales a favor del libre comercio mundial, bajo una concepción geopolítica hegemónica, basada en el 
establecimiento de convenios jurídico-políticos y tratados comerciales de orden supranacional.

Una herramienta del Estado neoliberal, señala Jaime Cárdenas, es la construcción de un Estado policíaco-militar, que abona a la discusión sobre los espacios de ingobernabilidad, inseguridad pública y desplazamiento forzado interno por esa causa en el territorio nacional. Estado policíaco-militar que en el caso de México se expresa en la justificación de la participación del ejército mexicano en actividades de seguridad pública, aunque recientemente se matiza con la conformación de una Guardia Nacional.

JaimePreciado y Ángel Florido (citados por Cárdenas, op. cit.) señalan que existe una doctrina de seguridad que evoluciona rápidamente aunque no necesariamente ofrece mejores resultados-incrementando recursos, fuerza e influencia política. Se confunden categorías como seguridad pública y seguridad nacional, y se promueven mecanismos de inteligencia con el uso de nuevas tecnologías —el uso de cámaras de seguimiento, por ejemplo-. Existe intercambio de información y se comparten tareas con otros gobiernos, particularmente con Estados Unidos - que en buena medida ve a México como su patio trasero-, y se incrementa el volumen de armas y equipos comprados al exterior para fortalecer al ejército y fuerzas policiacas de élite. En resumen, el ámbito de la seguridad pública es también trasnacional.

Es discutible, desde luego, establecer que las condiciones actuales de la seguridad pública en México obedezcan a un proceso inducido para el control social y consolidar la hegemonía norteamericana más allá del ámbito económico y comercial. Es necesario, sin embargo, considerarle como una posibilidad que parece más coyuntural. Es decir, aprovechar la situación objetiva - aumento en los índices de criminalidad- para impulsar los cambios que permitan mantener o consolidar la hegemonía preexistente, en el marco de un espectro global que se caracteriza por la conformación de bloques económicos, así como por el control de recursos estratégicos, particularmente el petróleo.

Espectro en el cual influyen decididamente las potencias militares y la industria armamentista, y que hasta cierto punto se justifica con el principio central de la gobernabilidad: la problemática y su resolución se circunscriben al ámbito gubernamental, no obstante que el gobierno se fortalezca con el apoyo de la comunidad internacional. 
Elma Trejo (2006) señala que el Acuerdo para la Seguridad y Prosperidad de América del Norte (ASPAN) buscó aumentar el apoyo y la seguridad en México, Estados Unidos y Canadá, tomando medidas específicas contra el terrorismo y el crimen organizado, particularmente tras los atentados terroristas del 11 de septiembre de 2001 en Estados Unidos. Se trata de un "Acuerdo Ejecutivo" firmado en marzo de 2005, por lo que sus agendas (seguridad y prosperidad) no tienen carácter de tratado internacional. En lo que toca al ámbito de la seguridad, la agenda toca aspectos tales como seguridad fronteriza y bio-protección; protección de infraestructura; mejoras en la seguridad aérea y marítima; así como agilizar el tránsito fronterizo, entre otras.

Es bajo tal enfoque que los acuerdos de cooperación bilateral en materia de seguridad toman forma. En 2007 surge la Iniciativa Mérida (Gobierno de la República, s.f.) que, en los hechos, es la plataforma más reciente y se enfoca a cuatro líneas estratégicas: desarticular a las organizaciones delictivas, fortalecer las instituciones públicas responsables, aumentar la seguridad fronteriza, y fortalecer la cohesión social en las comunidades más vulnerables a la violencia.

Sin embargo, César Estrada (2012) menciona que dicha iniciativa beneficia principalmente a las Fuerzas Armadas, que reciben hasta 60 por ciento de los recursos, la Procuraduría General de la República - actualmente fiscalía independiente- y la entonces Secretaría de Seguridad Pública - cuyas funciones se integraron a la Secretaría de Gobernación en el anterior sexenio para separarse nuevamente en el actual- Con énfasis en la dotación de equipo tecnológico para detección de drogas, comunicación y transporte, y dejando de lado el tema de la cohesión social, aspecto fuertemente vinculado con el desplazamiento forzado interno.

Ahora bien, la cuestión no sólo tiene que ver con los recursos provenientes del exterior para tales fines, pues igualmente en materia presupuestal se observa un importante incremento en los recursos dedicados al área de seguridad pública, por lo que es natural que surja la idea de la conformación de un estado policíaco. Cuestión a la que abonan iniciativas presidenciales tales como la Ley de Seguridad Nacional (2005) y la Ley de Seguridad Interior (DOF, 2017), aprobadas prácticamente sin el concurso de la ciudadanía.

Un análisis del Instituto Belisario Domínguez (IBD, 2017) indica que el gasto en seguridad pasó de 130 mil millones a 264 mil millones, aproximadamente, entre 2006 y 2016. Es decir, durante el periodo y 
en términos reales el gasto se duplicó con un ritmo mayor al del gasto neto federal (58 por ciento) y al del conjunto de la economía (23 por ciento). En términos relativos, pasó de representar 3.8 por ciento del gasto neto y 0.8 por ciento del PIB, a 4.9 por ciento del gasto neto y 1.4 por ciento del PIB en el mismo periodo. En la nueva administración federal, se prevé una reducción en términos reales.

El marco normativo también buscó orientarse a reforzar dicho estado policíaco militar, tal es el caso de la Ley de Seguridad Interior. Desde que se presentó la iniciativa generó controversia, pues facultaba a las Fuerzas Armadas para intervenir en el ámbito de la seguridad pública en apoyo de las entidades federativas y los municipios. Además, el concepto de seguridad interior inherente la subordina a la seguridad nacional:

Artículo 2. La Seguridad Interior es la condición que proporciona el Estado Mexicano que permite salvaguardar la permanencia y continuidad de sus órdenes de gobierno e instituciones, así como el desarrollo nacional mediante el mantenimiento del orden constitucional, el Estado de Derecho y la gobernabilidad democrática en todo el territorio nacional. Comprende el conjunto de órganos, procedimientos y acciones destinados para dichos fines, respetando los derechos humanos en todo el territorio nacional, así como para prestar auxilio y protección a las entidades federativas y los municipios, frente a riesgos y amenazas que comprometan o afecten la seguridad nacional en los términos de la presente Ley (DOF, 2017).

\section{DE HECHO, SE CONSIDERAN AMENAZAS A LA SEguRIDAD INTERIOR}

Artículo 4, Fracc. II. ... Las que afecten los principios establecidos en el artículo 3 y las contenidas en el artículo 5 de la Ley de Seguridad Nacional que tienen su origen en territorio nacional; las emergencias o desastres naturales en un área o región geográfica del país; las epidemias y demás contingencias que afecten la salubridad general; o las que afecten los deberes de colaboración de las entidades federativas y municipios en materia de seguridad nacional (DOF, 2017).

Ocupando un lugar relevante la preservación del Estado y el combate a la delincuencia organizada, no así la seguridad pública, según se desprende del contenido del mencionado artículo 5 de la Ley de Seguridad Nacional: 
Artículo 5.- Para los efectos de la presente Ley, son amenazas a la Seguridad Nacional:

I. Actos tendentes a consumar espionaje, sabotaje, terrorismo, rebelión, traición a la patria, genocidio, en contra de los Estados Unidos Mexicanos dentro del territorio nacional;

II. Actos de interferencia extranjera en los asuntos nacionales que puedan implicar una afectación al Estado Mexicano;

III. Actos que impidan a las autoridades actuar contra la delincuencia organizada;

IV. Actos tendentes a quebrantar la unidad de las partes integrantes de la Federación, señaladas en el artículo 43 de la Constitución Política de los Estados Unidos Mexicanos;

$\mathrm{V}$. Actos tendentes a obstaculizar o bloquear operaciones militares o navales contra la delincuencia organizada; ... (DOF, 2005).

En noviembre de 2018 la Suprema Corte de Justicia de la Nación declaró la inconstitucionalidad de la Ley de Seguridad Interior (LSI), pues su fin último era regular la participación de las Fuerzas Armadas en tareas de seguridad y combate a la delincuencia. Tampoco ajena al debate, particularmente desde el ámbito de los derechos humanos, con el arribo de la administración federal entrante tuvo lugar, aunque con matices, un paso en el mismo sentido de reforzar el estado policíaco-militar: la conformación de una Guardia Nacional de carácter presuntamente civil, pues estará conformada predominantemente por elementos de la policía naval y de la policía militar. El decreto de creación de este cuerpo reformó diversos artículos constitucionales y concitó el apoyo necesario en el Congreso de la Unión y los congresos locales y fue publicado en marzo de 2019.

\section{A manera de conclusión: seguridad pública y gobernanza}

La relación existente entre la percepción de inseguridad entre las personas, frecuentemente víctimas, que por ello deciden cambiar su lugar de residencia y las actividades de la delincuencia organizada es una cuestión que debe reconsiderarse. Se trata prácticamente de una estrategia de supervivencia, de ahí que se le considere desplazamiento forzado, ante el fracaso de la política de seguridad pública instrumentada por el gobierno mexicano, en la que uno de los eslabones más débiles es el vínculo con estados y municipios.

A pesar del aumento sostenido del gasto federal en seguridad en el período señalado párrafos arriba, de acuerdo con el estudio citado 
(IBD, 2017), el peso del Fondo de Aportaciones para la Seguridad Pública (FASP) en el gasto total en seguridad se ha reducido, pasando de 9.3 por ciento en 2006 a 2.8 por ciento en 2016. Además, en forma acumulada, la distribución de los recursos entre las entidades federativas se asocia más con el tamaño de la población que con la incidencia delictiva. Es decir, mientras se fortalecen las instituciones más avocadas a la seguridad nacional, en particular el Ejército y la Armada de México, no se observa el mismo énfasis para fortalecer a las encargadas de la seguridad pública en el ámbito regional y local, limitando el impacto de la intervención de las primeras.

Luis Aguilar, citado por José Ma. Serna (2010), establece que el concepto de gobernanza se distingue por contemplar que la elección del camino deseado no es prerrogativa gubernamental exclusiva, pues distintos actores se integran al debate y la acción, incluso con agendas propias, incorporando al diseño e instrumentación de las políticas públicas, así como a la prestación de servicios gubernamentales, mecanismos de participación social y factores de mercado. Se trata de formas de asociación y cooperación entre los sectores público, privado y social, encaminadas a resolver problemas sociales no resueltos por un gobierno rebasado en sus alcances financieros, técnicos u operativos.

Es importante mencionar, indica Serna (2010), que el concepto fue introducido como parte de un "nuevo lenguaje" empleado por organismos internacionales, en particular el Banco Mundial y el Fondo Monetario Internacional, que se transmitió a los Estados y empezó a ser utilizado por sus gobiernos, en buena medida como condición asociada a los préstamos que estas instituciones otorgaron a países en desarrollo y las economías emergentes del antiguo bloque comunista.

Lo anterior bajo el paradigma del adelgazamiento del Estado y el fomento del libre mercado, ante el agotamiento del Estado del Bienestar. Lo que nos lleva a una cuestión elemental: el Estado tiene una función social, antes que económica. En ese sentido, los valores de eficacia y eficiencia, y el logro de resultados, tendrían que ser medidos en términos de bienestar social antes que en términos de costo-beneficio. Tenor en el cual el desplazamiento forzado interno habría de percibirse como problemática social y no como un costo marginal derivado de las intervenciones gubernamentales en materia de seguridad pública.

Cristina Zurbriggen (2011) menciona que los mecanismos para regular a una sociedad son por autoridad o jerarquía, por el mercado o económico, o por redes auto-organizadas y asociaciones o heterárquico. 
Si bien dichos mecanismos coexisten en diferente medida, lo que caracteriza a la gobernanza es el dominio del mecanismo heterárquico. Sin embargo, en el contexto latinoamericano la gobernanza surge en un contexto sociopolítico particular, caracterizado en muchos casos por la existencia de gobiernos autoritarios y sociedades atomizadas, tras un cambio de modelo socioeconómico impulsado desde el exterior.

Condiciones en que las transformaciones democráticas en México resultaron parciales a pesar de los esfuerzos por transformar el sistema electoral, ampliar el abanico de posibilidades para la participación ciudadana y romper con prácticas como el corporativismo o el clientelismo. A lo que se añade el surgimiento de organizaciones y movimientos sociales, luego cooptados o reprimidos.

Si bien se ampliaron los márgenes de debate, en realidad las redes auto-organizadas y las asociaciones civiles han tenido poca influencia en las decisiones de gobierno, incluida la esfera de la seguridad pública. No así los factores de poder asociados al gran capital nacional y trasnacional, beneficiados por la apertura comercial y financiera, y la privatización de empresas y servicios públicos, entre otras:

Llamadas reformas de primera generación, cuyo énfasis estuvo puesto en desregular y reducir el gasto, el tamaño y la intervención del Estado en la economía y la sociedad... (Luego) se promocionan las reformas de segunda generación. Estas últimas, si bien mantuvieron el signo neoliberal, plantearon la necesidad de fortalecer las capacidades estatales y generar instituciones eficientes que garantizaran el funcionamiento de un mercado competitivo (Zurbriggen, 2011: 46).

En ese sentido, las acciones impulsadas se orientaron con mayor énfasis a regular la sociedad por el mercado o por la autoridad. No es casual, por ende, que la implantación de la gobernanza en los países en desarrollo careciera de los elementos esenciales para la creación de políticas públicas más eficaces y eficientes, a la vez que democráticas.

De acuerdo con Johan Olsen, citado por Zurbriggen (2011), no se consideraron los procesos históricos y las relaciones de poder que sustenta la toma de decisiones al interior de los países. Lo que en el caso de México se concreta en la transición de un régimen presidencialista y autoritario, a otro donde la democracia prácticamente se acota a los procesos electorales, y perviven prácticas corporativistas y clientelares en lo que a participación ciudadana se refiere.

De tal suerte, si el enfoque desde el poder público es fortalecer al estado policíaco-militar, el rol de los desplazados internos en la toma 
de decisiones de política de seguridad pública, dada su vulnerabilidad en los lugares de origen y las implicaciones de un cambio de residencia no planeado en los lugares de destino, por definición es marginal.

Existen desde luego otros actores que se involucran en el debate y plantean la necesidad de atender la problemática del desplazamiento forzado interno por motivos de inseguridad pública. Tal es el caso de las defensorías de derechos humanos de carácter institucional o social, nacionales y extranjeras. Sin embargo, su influencia y alcances son limitadas por no decir meramente testimoniales.

Sin obviar que la gobernanza implica ceder espacios de poder y áreas de influencia. Cuestión de fondo es que sus voces son escuchadas, pero no tienen suficiente peso específico para influir en una arena pública donde confluyen intereses geopolíticos, el gran capital nacional y extranjero, así como la propia estructura del poder público-político y el poder económico en el país. Permeada por actividades de actores no visibles tales como crimen organizado, bandas delictivas, guardias blancas y grupos paramilitares, cobijadas hasta cierto punto por una estrategia, si así puede llamarse, laissez faire-laissez passer.

Los resultados electorales de 2000 permitían prever un cambio de régimen político en México, pero no fue así. El nuevo gobierno y los subsecuentes enfocaron sus esfuerzos a materializar las reformas estructurales del Estado neoliberal y continuar con la lógica de la preeminencia del mercado, aunque sin los "controles" logrados por el régimen de partido único. Además de que produjo un incremento en la criminalidad, la gobernanza y su correlato el fortalecimiento de la sociedad civil, fue relegada.

Como se observa en la Figura 1, un punto de quiebre fue la llegada de un gobierno con severa crisis de legitimidad derivada del proceso electoral de 2006, cuya ruta para legitimarse fue declarar la guerra al crimen organizado, sin una concepción clara de sus dimensiones y enraizamiento social, pero sí bajo los cánones del estado policíacomilitar. Lo que dejó poco espacio para la gobernanza y relegó a los derechos humanos, además de propiciar el escenario para el desplazamiento forzado por motivos de inseguridad pública.

Otro punto de quiebre fue la llegada de un gobierno con filiación política distinta en 2012. Los datos sugieren que comenzaron a operar adecuadamente los nuevos controles, pero resultó un éxito temporal. Nuevamente no hubo lugar para la gobernanza, los derechos humanos 
siguieron relegados y el escenario propicio para el desplazamiento forzado por motivos de inseguridad pública se conservó.

Con los resultados electorales de 2018, en diversos sectores se esperaba un cambio de régimen político, que para sectores de distinto giro social, económico o político está quedando a deber. En el caso concreto de la seguridad pública está en marcha un cambio de estrategia que aún no ofrece resultados positivos. Por su parte, la Comisión Nacional de los Derechos Humanos pretende presentar una iniciativa de ley general sobre desplazamiento forzado interno. En esa tesitura, aún está por verse el rol que habrá de jugar la ciudadanía para saber si habrá lugar para un proceso de gobernanza que incida en el fenómeno del desplazamiento forzado interno, dándole lugar a su reconocimiento como problemática social, tanto como en la fundamentación jurídica necesaria para su atención.

En lo que toca al ámbito académico, es necesario profundizar en el estudio del fenómeno considerando otras perspectivas analíticas y mayor profundidad, pues este trabajo apenas esboza la naturaleza y comportamiento del fenómeno en estudio. Sin duda una de las líneas donde es necesario arrojar más luces es en la cifra negra de delitos. También, estudiar las estrategias de atención a delitos de alto impacto como es el caso del secuestro, sin dejar de lado la desaparición de personas. Finalmente, los caminos a seguir para la atención a las personas desplazadas de manera forzada por cuestiones de seguridad pública en los lugares de destino, entendida como un caso especial de migración cuyas causas son especialmente sensibles.

\section{REFERENCIAS BIBLIOGRÁFICAS}

Aponte Cardona, Alejandro. (2011). "Desplazamiento forzado, sistema interamericano y derecho penal interno. Hacia una confluencia racional y consistente de diversos ámbitos de protección de derechos humanos", en Sistema Interamericano de Protección de los Derechos Humanos y Derecho Penal Internacional, Uruguay, Konrad-Adenauer-Stiftung, T. II, 71-120. Consultado el 31 de enero de 2018 en https://bit.ly/2GGvjhk

Cárdenas, Jaime. (2017). Del Estado absoluto al Estado neoliberal, México, Instituto de Investigaciones Jurídicas, Universidad Nacional Autónoma de México. Consultado el 19 de julio de 2018 en https://bit.ly/2JLcdDE

Chase, Luis Enrique. (2002). "La reforma del estado", en Fernández Ruiz, Jorge (coord.) Perspectivas del derecho administrativo en el siglo XXI, México, Instituto de Investigaciones Jurídicas, Universidad Nacional 
Autónoma de México, 151-162. Consultado el 18 de julio de en https:// bit.ly/2M3TVPP

Comisión Interamericana de Derechos Humanos. (CIDH). (2015). Situación de los derechos humanos en México, México, Comisión Interamericana de los Derechos Humanos. Consultado el 04 de febrero de 2018 en https:// bit.ly/2suvB2Q

Comisión Mexicana de Defensa y Promoción de los Derechos Humanos (CMDPDH). (2014). Desplazamiento interno forzado en México, México, Comisión Mexicana de Defensa y Promoción de los Derechos Humanos. Consultado el 31 de enero de 2018 en https://bit.ly/2003bMV

Comisión Nacional de los Derechos Humanos. (CNDH). (2016). Informe Especial sobre Desplazamiento Forzado Interno (DFI) en México, México, Comisión Nacional de los Derechos Humanos. Consultado 01 de agosto de 2018 en: https://bit.ly/1UUiQq7

Cruz Roja Internacional. (CRI). (1998). "Principios Rectores de los desplazamientos internos", Revista Internacional de la Cruz Roja, 30 de septiembre de 1998. Consultado el 07 de febrero de 2018 en https://bit. ly/2dGOAxW

Diario Oficial de la Federación. (DOF). (2005). Ley de Seguridad Nacional, México, Diario Oficial Federación, 26 de diciembre de 2005.

Diario Oficial de la Federación. (DOF). (2011). Constitución Política de los Estados Unidos Mexicanos, Artículo 1oㅡ. México, Diario Oficial de la Federación, 10 de junio de 2011.

Diario Oficial de la Federación. (DOF). (2017). Ley de Seguridad Interior. México. Diario Oficial de la Federación, 21 de diciembre de 2017.

Estrada, César. (2012). "La Iniciativa Mérida y el combate al narcotráfico. Cooperación bajo concepciones Inadecuadas", Revista de El Colegio de San Luis, II(3), 266-279. Consultado el 25 de julio de 2018 en https://bit. ly/2XjtjQR

García, Máynez, Eduardo. (2002). Introducción al estudio del derecho. México: Porrúa.

Gobierno de la República. (s.f.). "Cooperación Bilateral sobre Seguridad", México, Gobierno de la República. Consultado el 25 de julio de 2018 en https://bit.ly/2Xjt6NK

Instituto Belisario Domínguez. (IBD). (2017). Panorama del Gasto Federal en Seguridad, 2006-2016, México, Instituto Belisario Domínguez, Senado de la República. Consultado el 25 de julio de 2018 en https://bit. ly/2SW0QSC

Instituto Nacional de Estadística y Geografía. (INEGI). (2016). Encuesta Nacional de Victimización y Percepción sobre Seguridad Pública 2016, México, Instituto Nacional de Estadística y Geografía. Consultado el 15 de septiembre de 2017 en https://bit.ly/2GWqUpH 
Instituto Nacional de Estadística y Geografía. (INEGI). (2016a). "Encuesta Nacional de Victimización y Percepción sobre Seguridad Pública (ENVIPE) 2016", Boletín de Prensa Núm. 399/16, 27 de septiembre de 2016. Consultado 15 de diciembre de 2017 en https://bit.ly/2dhts3d

Instituto Nacional de Estadística y Geografía. (INEGI). (2011). Encuesta Nacional de Victimización y Percepción sobre Seguridad Pública 2011, México, Instituto Nacional de Estadística y Geografía. Consultada 15 de septiembre de 2017 en https://bit.ly/2IwH8s4

Jiménez, William y César, Ramírez. (2008). Gobierno y Políticas Pública, Colombia, Escuela Superior de Administración Pública. Consultado 18 de julio de 2018 en https://bit.ly/2Skw1Sq

Periódico Oficial del Gobierno del Estado de Guerrero. (POGEG). (2014). Ley Número 487 para Prevenir y Atender el Desplazamiento Interno en el Estado de Guerrero, México, Periódico Oficial del Gobierno del Estado de Guerrero, Núm. 58, Alcance I, 22 de Julio de 2014.

Serna de la Garza, José Ma. (2010). "El concepto de gobernanza", en Globalización y Gobernanza: Las transformaciones del Estado y sus implicaciones para el derecho público, México, Instituto de Investigaciones Jurídicas, Universidad Nacional Autónoma de México, pp. 21-51. Consultado 26 de julio de 2018 en https://bit.ly/2Ep7gky

The Global Overview. (2014). Global Overview 2014. People internally displaced by conflict and violence, Noruega, Internal Displacement Monitoring Centre. Consultada 01 de agosto de 2018 en https://bit. ly/2tzceEU

Trejo, Elma del Carmen. (2006). Alianza para la Seguridad y la Prosperidad de América del Norte (ASPAN), México, Cámara de Diputados. Consultada 23 de julio de 2018 en https://bit.ly/2czbCsm

Zapata, John. (2014). "La teoría del estado fallido: entre aproximaciones y disensos", Revista de Relaciones Internacionales, Estrategia y Seguridad, 9(1), 87-110. Consultado 18 de julio de 2018 en https://bit.ly/2p7X2fo

Zurbriggen, Cristina. (2011). "Gobernanza: una mirada desde América Latina", en Perfiles Latinoamericanos, Núm. 38, 39-64. Consultado 26 de julio de 2018 en https://bit.ly/2Xix7Cc

\section{RESUMEN CURRICULAR DEL AUTOR}

\section{Ignacio César Cruz Islas}

Profesor Investigador. El Colegio del Estado de Hidalgo. Doctor en Estudios de Población por El Colegio de México. Distinguido con nombramiento del Sistema Nacional de Investigadores Nivel I (20162022), así como con el Premio Fundación BBVA BANCOMER a la 
Excelencia COLMEX (2012). Con experiencia laboral como investigador en el Centro de Investigación y Estudios Avanzados de la Población de la UAEMex (2016) y la Secretaría General del CONAPO (20012007), así como Asesor del Programa Estatal de Cooperación UNFPAGuerrero (2000) y Asistente de la Comisión de Población y Desarrollo de la Cámara de Diputados (1999).

Dirección electrónica: icruz@elcolegiodehidalgo.edu.mx 